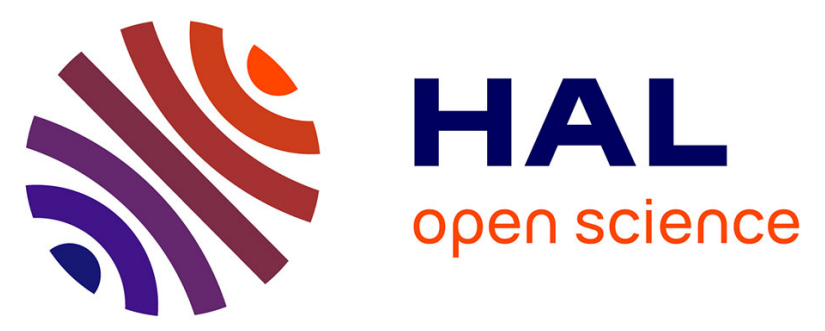

\title{
Comparing nutritional, economic, and environmental performances of diets according to their levels of greenhouse gas emissions
}

Louise Seconda, Julia Baudry, Benjamin Allès, Christine Boizot-Szantai, Louis-Georges Soler, Pilar Galan, Serge Hercberg, Brigitte Langevin, Denis Lairon, Philippe Pointereau, et al.

\section{To cite this version:}

Louise Seconda, Julia Baudry, Benjamin Allès, Christine Boizot-Szantai, Louis-Georges Soler, et al.. Comparing nutritional, economic, and environmental performances of diets according to their levels of greenhouse gas emissions. Climatic Change, 2018, 148 (1-2), pp.155-172. 10.1007/s10584-018-2195-1 . hal-02091331

\section{HAL Id: hal-02091331 \\ https: / hal-amu.archives-ouvertes.fr/hal-02091331}

Submitted on 6 May 2019

HAL is a multi-disciplinary open access archive for the deposit and dissemination of scientific research documents, whether they are published or not. The documents may come from teaching and research institutions in France or abroad, or from public or private research centers.
L'archive ouverte pluridisciplinaire HAL, est destinée au dépôt et à la diffusion de documents scientifiques de niveau recherche, publiés ou non, émanant des établissements d'enseignement et de recherche français ou étrangers, des laboratoires publics ou privés. 
Title

Comparing nutritional, economic and environmental performances of diets according to their levels of Greenhouse Gas Emissions

\section{Author Names}

Louise Seconda ${ }^{1,2^{*}}$, Julia Baudry ${ }^{1}$, Benjamin Allès ${ }^{1}$, Christine Boizot-Szantai ${ }^{3}$, Louis-Georges Soler $^{3}$, Pilar Galan ${ }^{1}$, Serge Hercberg ${ }^{1,4}$, Brigitte Langevin ${ }^{5}$, Denis Lairon ${ }^{6}$, Philippe Pointereau ${ }^{5}$, and Emmanuelle Kesse-Guyot ${ }^{1}$

\section{Author Affiliations}

${ }^{1}$ Equipe de Recherche en Epidémiologie Nutritionnelle (EREN), Université Paris 13, Inserm (U1153), Inra (U1125), Centre d'Epidémiologie et Statistiques Paris Cité, Cnam, COMUE Sorbonne-Paris-Cité, 93017 Bobigny, France; I.seconda@eren.smbh.univ-paris13.fr (L.S. ORCID : 0000-0003-3460-5457), j.baudry@eren.smbh.univ-paris13.fr (J.B.);

b.alles@eren.smbh.univ-paris13.fr (B.A. ORCID : 0000-0002-7970-171X (B.A.);

p.galan@uren.smbh.univ-paris13.fr (P.G.); s.hercberg@uren.smbh.univ-paris13.fr (S. H. ORCID : 0000-0002-3168-1350); e.kesse@eren.smbh.univ-paris13.fr (E.K.-G. ORCID : 00000002-9715-3534)

${ }^{2}$ Agence de l'Environnement et de la maîtrise de l’Energie, 20, avenue du Grésillé- BP 90406 49004 Angers Cedex 01, France

${ }^{3}$ INRA Aliss UR 1303, 94200 Ivry sur Seine, France; Christine.Boizot@ivry.inra.fr (C.B.-S.); Igsoler@ivry.inra.fr (L.-G.S.)

${ }^{4}$ Département de Santé Publique, Hôpital Avicenne, 93017 Bobigny, France; s.hercberg@uren.smbh.univ-paris13.fr (S.H.)

${ }^{5}$ Solagro, 75, Voie TOEC, 31000 Toulouse, France ; b.langevin@laposte.net (B. L.); philippe.pointereau@solagro.asso.fr (P.P.) 
${ }^{6}$ Nutrition, Obésité et Risque Thrombotique (NORT), Aix Marseille Université, INSERM, UMR S 1062, INRA 1260, 13005 Marseille, France; denis.lairon@orange.fr ORCID : 0000-0001-99413742 (D.L.)

\section{*Corresponding author}

Louise Seconda

Equipe de Recherche en Epidémiologie Nutritionnelle (EREN)

SMBH Université Paris 13

74 rue Marcel Cachin, 93017 Bobigny, France

Phone number: + 33148388979

Fax number: + 33148388931

I.seconda@eren.smbh.univ-paris13.fr 


\section{Abstract}

In response to climate change, reduction of GHGEs (greenhouse gas emissions) from food systems is required. Shifts of agricultural practices and dietary patterns could reduce GHGEs. We aimed to characterize observed diets with different levels of GHGEs, and compare their nutritional, economic and environmental performances.

Food consumptions of 34,193 French adults participating in the NutriNet-Santé cohort were assessed using a food frequency questionnaire. Nutritional, environmental and economic indicators were computed for each individual diet. Adjusted means of food group intakes, contribution of food groups to dietary GHGEs, nutritional, environmental and economic indicators were compared between weighted quintiles of GHGEs.

Diets with high GHGEs (ranging from 2,318 to 4,099 $\mathrm{kgCO}_{2 \mathrm{eq}} / \mathrm{y}$ ) contained more animalbased food, and provided more calories. Few differences were found for unhealthy food (alcohol or sweet/fatty food) consumption across the categories of dietary GHGEs. Diets with low GHGEs were characterized by a high nutritional quality. Primary energy consumption and land occupation increased with GHGEs (from Q1: 3,978 MJ/y $(95 \% \mathrm{Cl}=3,958-3,997)$ to Q5: $8,980 \mathrm{MJ} / \mathrm{y}(95 \% \mathrm{Cl}=8,924-9,036))$ and (from Q1: $1,693 \mathrm{~m}^{2} / \mathrm{y}(95 \% \mathrm{Cl}=1,683-1,702)$ to Q5: $\left.7,188 \mathrm{~m}^{2} / \mathrm{y}(95 \% \mathrm{Cl}=7,139-7,238)\right)$ respectively. Finally, participants with lower GHGEs relateddiets were the highest organic food consumers. After adjustment for sex, age and energy intake, monetary diet cost increased with GHGEs (from Q1: $6.89 € / y(95 \% \mathrm{Cl}=6.84-6.93)$ to Q5: 7.68€/y $(95 \% \mathrm{Cl}=7.62-7.74))$.

Based on large observational cohort, this study provides new insights concerning the potential of current healthy and emergent diets with low monetary cost and good nutritional quality to promote climate mitigation. However, the question of a large acceptability remains. 


\section{Keywords}

Climate change, Dietary pattern, GreenHouse Gas Emissions, Organic food Abbreviations

AMAPs: Associations Supporting Small Farming

ANCOVA: Analysis of Covariance

BMI: Body Mass Index

$\mathrm{Cl}$ : Confidence Intervals

CU: Consumption Unit

$\mathrm{CH}_{4}$ : Methane

$\mathrm{CO}_{2}$ : Carbon dioxyde

GHG: GreenHouse Gas

GHGEs: GreenHouse Gas Emissions

INSEE: National Institute of Statistical and Economic Studies

IPAQ: International Physical Activity Questionnaires

IPCC: Intergovernmental Panel on Climate Change

LCA : Life Cycle Assessment

mPNNS-GS: modified Programme National Nutrition Santé Guidelines Score

$\mathrm{N}_{2} \mathrm{O}$ : Nitrous oxide

Org-FFQ: Organic Food Frequency Questionnaire

PANDiet: Diet Quality Index Based on the Probability of Adequate Nutrient Intake

Q: Quintile

UK: United Kingdom

WHO: World Health Organisation 


\section{Introduction:}

The last IPCC (Intergovernmental Panel on Climate Change) report concluded with 95\% certainty that human activities have been the primary cause of global warming since the middle of the $20^{\text {th }}$ century (1). In response to the temperature rise and its harmful consequences, deep reduction of greenhouse gas emissions (GHGEs) is required, notably in food systems which account for $19-29 \%$ of global anthropogenic GHGEs (2). Three gases contribute for almost $91.5 \%$ to the agricultural total emissions, nitrous oxide $\left(\mathrm{N}_{2} \mathrm{O}\right)$, methane $\left(\mathrm{CH}_{4}\right)$ and carbon dioxide $\left(\mathrm{CO}_{2}\right) . \mathrm{CH}_{4}$ and $\mathrm{N}_{2} \mathrm{O}$ emissions are generally limited to the agricultural phase, while $\mathrm{CO}_{2}$ emissions are spread out among the whole food chain (3). At the agricultural stage, some measures and innovative processes (e.g. enhancing carbon removals, optimising nutrient use, etc.) have emerged to reduce the GHGEs (4). However, several studies concluded that agricultural technical options are not sufficient and important shifts in dietary patterns by a large proportion of the world population will be required to achieve the necessary climate mitigation (4-6).

In particular, the modelled French scenario Afterres 2050 plans a mandatory $50 \%$ cut in agricultural GHGEs by 2050, by changing the French diet, implementing agro ecological practices, and reducing energy consumption (7). This scenario applies the road map of the European Commission for a low carbon economy with the objective of $-42 \%$ to $-49 \%$ GHGEs (without $\mathrm{CO}_{2}$ ) in 2050 compared to 1990 (8).

Low GHGEs diets have already been estimated using modelling approaches or depicted using observational data (8-10).

However, due to the small size of the samples restraining the variety of dietary patterns, or the constraints included in the models when performing optimization or simulation studies, issues as regards the reality and the acceptability of such diets in large populations remain 
(9). Moreover, the consistency between eco-friendly dietary practices and nutritional requirements were scarcely evaluated. A high-nutritional quality diet has previously been associated with greater environmental impact in some studies $(9,12-14)$. Conversely, a recent meta-analysis concluded that a shift from Western to sustainable dietary patterns generally provided benefits for the environment and health (10). Finally, published findings about the associations between monetary costs and low GHGEs diets are contradictory $(9,15)$.

As primary production is responsible for a large proportion of carbon footprints (16), and given the high diversity of the current farming systems, the model of food production (conventional or organic) seems an important factor to take into account, for the assessment and comparison of the environmental performances of various diets (17-19). Also, most existing studies considered a single environmental indicator (11) while the assessment of several environmental indicators can contribute to consolidate the validity of results for different environmental dimensions (11).

In that context, we aimed to depict the diets observed in a large sample of adults with different levels of GHGEs in terms of food composition while accounting for the mode of food production. We also compared their nutritional, environmental and economic characteristics.

\section{Materials and methods:}

\section{$\underline{\text { Study design and participants }}$}

The NutriNet-Santé Study is an ongoing web-based prospective observational cohort of French adult volunteers, launched in May 2009 with a scheduled follow-up of 10 years. The design has been comprehensively described elsewhere (20). The inclusion in the cohort is 
based on a set of self-administered web-based questionnaires on dietary intake, health and anthropometric, socio-demographic and lifestyle characteristics. Included volunteers are regularly invited to update their data and to fill in optional complementary questionnaires.

\section{$\underline{\text { Standard protocol approvals, registrations and participant consents }}$}

The study was conducted observing the guidelines from the Declaration of Helsinki, and all protocols were approved by the Institutional Review Board of the French Institute for Health and Medical Research (IRB INSERM no. 0000388FWA00005831) and the Commission Nationale de l'Informatique et des Libertés (CNIL no. 908450 and no. 909216). Participant informed consents were signed by all volunteers with an electronic signature. The NutriNetSanté study is registered in ClinicalTrials.gov (NCT03335644).

\section{Data collection}

\section{Assessment and treatment of dietary data}

Usual dietary food intake was assessed using an organic semi-quantitative food frequency questionnaire (Org-FFQ)(21), based on a previously validated questionnaire (22). Participants had to report their frequency (yearly, monthly, weekly or daily units) of consumption over the past year for 264 items (food and beverage). Standard portion sizes were described as typical household measurements or using colour standardized and validated photographs. Food intakes in grams per day were obtained by multiplying the portion size and frequency. Food items were grouped into 15 food groups for descriptive purpose. Nutrient intakes were estimated using nutritional values from the published NutriNet-Santé food composition table (23). 
Moreover, to assess the level of organic food consumption, participants were asked for each item except those that do not exist in organic form how often they came from organic source (identified through label certification) through a 5-point ordinal scale ranging from "never" to "always". A weight of $0,0.25,0.5,0.75$ and 1 was applied to the five respective frequencies to obtain the share of organic food in the diet for each item and overall (without water). The over-reporters and under-reporters were identified by a ratio of energy intake to energy requirement (estimated with the Schofield equations (24) according to sex, age, weight and height) below or above the cut-offs (0.35 and 1.93).

Finally, three dietary indicators were also computed to assess the overall nutritional quality of the diet: 1) the energy density of the diet, 2) the nutrient-based PANDiet score (25) measures the probability of adequate nutrient intake based on current nutrient reference values and 3) the food-based mPNNS-GS (26) (modified Programme National Nutrition Santé Guideline-Score) assesses adherence to the French official nutrition guidelines. A detailed description of these scores is proposed in the Supplemental Material 1.

\section{Assessment of the environmental impacts of the diet}

A database gathering the environmental indicators associated with the Org-FFQ items accounting for the method of production (conventional or organic) was developed. To do that, we used DIALECTE, a comprehensive tool developed by Solagro (Toulouse, France) (27) which aims to describe French farming systems and to assess the environmental performance of farms, which contained environmental impacts related to 60 raw products. The selected indicators were the GHGEs (in $\mathrm{kg} \mathrm{CO}_{2 \mathrm{eq}} / \mathrm{kg}$ ), the primary energy consumption (in $\mathrm{MJ} / \mathrm{kg}$ ) and land occupation (in $\mathrm{m}^{2} / \mathrm{kg}$ ). As detailed in the first part of the Supplemental Material 2, the perimeter of DIALECTE environmental impact assessment included the 
upstream processes such as the production of inputs or energy provision, while conditioning, transport, processing, storage and recycling were excluded due to missing information for the organic sector. The database was completed with published literature data, to obtain the environmental impact in organic and conventional of 92 raw agricultural products. As our objective was to assess the environmental impacts of diets, it was necessary to conduct a set of conversions (described in the Supplemental Material 2) from the environmental impacts assessed for raw agricultural products in order to estimate environmental impacts for food items of the food frequency questionnaire. Briefly, the items were decomposed into ingredients. The environmental impacts of ingredients (organic and conventional) were assessed from raw products by applying an economic allocation (accounting for co-products) and cooking and edibility coefficients $(28,29)$. The individual environmental impacts of diet were estimated by multiplying the environmental impacts by food quantity consumed $(\mathrm{g} / \mathrm{d})$ accounting for the method of food production.

\section{Assessment of the monetary cost of diet}

Volunteers were also invited to fill in a complementary questionnaire focusing on attitudes and motivations as regards food choices inquiring the place of purchase.

A database gathering the prices of the 264 items of the Org-FFQ accounting for the place of purchase and the food production mode (organic vs. conventional) was developed (30). The 2012 KANTAR database was used to collect the prices from supermarkets and specialized stores (31). Additionally, members of the Bioconsom'acteurs association collected 1,100 additional prices in autumn 2014 and 862 prices in spring 2015 over nine French metropolitan regions, in short supply chains (local markets or associations supporting small farming (AMAPs)). The individual monetary cost of diet was calculated by multiplying price 
$(€ / g)$ by food quantity consumed $(\mathrm{g} / \mathrm{d})$ accounting for the place of purchase and the method of food production.

\section{Covariates}

Sociodemographic and lifestyle data were collected using the inclusion set and yearly update questionnaires. Data used was the closest to the date of the completion of the Org-FFQ.

Sociodemographic data included sex, age (over 18), education (< high school diploma, high school diploma and post-secondary graduate), place and area of residence (rural community, urban units with a population smaller than 20,000 inhabitants, between 20,000 and 200,000 inhabitants and higher than 200,000 inhabitants) and monthly income per household unit $(<1,200$ euros, between 1,200 and 1,800 euros, between 1,800 and 2,700 euros and $>2,700$ euros per household unit) obtained using the income by month in the household and the composition of the household.

Lifestyle variables were smoking status (former, occasional, current, or non-smoker), level of physical activity (as measured by the IPAQ (International Physical Activity questionnaires (32-34)), weight and height assessed by a health operator, medical doctor, or from selfmeasurement guided by standardized procedures. Body mass index (BMI) $\left(\mathrm{kg} / \mathrm{m}^{2}\right)$ was computed.

\section{Statistical analysis}

A total of 37,685 adult participants completed the Org-FFQ. We excluded participants who were under/over-reporters $(n=2,109)$, as well as those with missing covariates $(n=391)$, living abroad $(n=716)$ or in overseas territories $(n=249)$, leading to a sample of 34,193 volunteers. 
Data concerning monetary cost of diet were collected from a subsample of volunteers $(N=29,210)$ who completed the questionnaire on place of purchase.

The sample was weighted, in order to improve representativeness of the population identified, using the SAS Calmar macro, developed by the National Statistics and Economic Studies Institute (INSEE) (35). The weighting was made by gender, taking into account the age, educational level, area of residence and whether or not the household included any children. We used the 2009 national Census data as reference. . Then, participants were divided into weighted quintiles according to diet-related GHGEs. Sociodemographic and lifestyle characteristics were compared across quintiles: means with standard deviation or percentages were presented and overall differences were tested using Mantel-Haenzel trend $\chi 2$ or linear contrast tests.

The adjusted means for sex, age and energy intake with the residual method (36) and $95 \% \mathrm{Cl}$ of food group consumption by diet according to GHGEs were calculated. The contribution of each food group to the total dietary GHGEs were also assessed across quintiles.

Finally, analyses of covariance (ANCOVA) models according to the observed margins (this option changes the coefficients to be proportional to those observed in the input data set) were performed to identify the associations between GHGEs and dietary, health, other environmental and economic indicators. When appropriate, a log-transformation was applied to improve the normality of continuous variables (namely for expenditure, primary energy consumption and land occupation). Post-hoc differences across categories were evaluated after adjustment for multiple testing using the Dunnett's correction. P values for linear trend across quintiles were estimated using linear contrast tests. The type I error was set at $5 \%$ for all statistical tests.

SAS 9.4 software (SAS Institute Inc., Cary, NC, USA) was used to perform all analyses. 


\section{Results}

Participant characteristics

The sample was composed of 34,193 volunteers with a mean age of $53.3(\mathrm{SD}=14.0)$, and 75.5\% women (before weighting).

Table 1 shows the sociodemographic and lifestyle characteristics of participants across quintiles of diet-related GHGEs. Participants in Q1 were more often women, younger, as well as more often large town inhabitants, physically active, never smokers, and post-secondary graduate. The level of income per household unit did not seem associated with GHGEs. Lower dietary GHGEs were associated with a greater part of organic food in the diet.

\section{Food intakes according to quintiles of dietary GHGEs}

Concerning the dietary characteristics, the prominent gap across quintiles of diet-related GHGEs concerned the intake of red meat (Table 2). Red meat intake was positively associated with GHGEs. A similar trend was observed to a lesser extent for white meat, mixed dishes and dairy products. The average consumption of sweet and fatty products was not significantly different across quintiles of GHGEs. Participants exhibiting the lower GHGEs consumed more starches, whole grains, fruits, vegetables, and soya products.

The relative contributions of food groups to total GHGEs showed strong disparities across quintiles (Figure 1). The contribution of red meat to dietary GHGEs increased across quintiles, while opposite trends were observed for fruit and vegetables and starchy foods.

\section{Nutritional characteristic of participants}


Table 3 shows the nutritional characteristics of participants according to the diet-related GHGEs. First, caloric intake linearly increased with the GHGEs of the diet as well as the energy density. Participants in Q4 and Q5 showed the lowest dietary quality (mPNNS-GS and PANDiet). However, for the first three quintiles, the differences in the nutritional quality of diet are less obvious. Indeed, the participants in Q3 exhibited the better compliance with the French nutritional guidelines, while Q1 participants presented the highest PANDiet score, reflecting a good adequacy match to nutrients guidelines. However, the highest PANDiet score in Q1 was mostly explained by higher moderation sub-score than high adequacy subscore which was higher in Q3.

Finally, the mean BMI of participants increased along with the level of diet GHGEs (Q1 to Q5).

\section{Environmental and economic characteristics of diet}

Table 4 shows the data for environmental and economic indicators according to the level of GHGEs. Two adjusted models are presented with and without adjustment for energy intake. Land occupation, primary energy consumption to produce foods and diet purchase increased with the level of GHGEs from the diet.

All these associations remained significant after adjustment for energy intake although the magnitudes of the differences were reduced.

\section{Discussion}

The present study showed, from a large adult cohort, that diet-related with low GHGEs are characterized by a low intake of food from animal origin and provided fewer calories. They were also characterized by a high nutritional quality and a higher proportion of organic food. 
No or few differences in consumption of unhealthy food (alcohol or sweet and fatty products) across categories of dietary GHGEs were observed. Concerning environmental indicators, a diet with low GHGEs was produced with a minimum primary energy consumption and land occupation.

Recent studies, based on modelled or observed diets, have reported the major contribution of animal products to diet-related GHGEs. (37-40). At the individual level, a decrease in animal product consumption, especially from ruminants, remains a necessary key challenge to maintain global temperature increase below $2^{\circ} \mathrm{C}(5)$. Moreover, a lower level of animal production does not reduce only GHGEs, but it is also of land occupation and energy saving $(9,41,42)$.

In our study, the average dietary energy intake increased across quintiles of diet-related GHGEs. This finding is consistent with previous studies reporting a linear relationship between energy intake and dietary GHGEs $(40,43)$. Based on these observational data, it appears that the lowest levels of energy intake are observed among some subgroups of the population (Q1 \& Q2) while others have higher energy intakes and animal food baseddietary patterns (Q4 \& Q5).

Moreover, we observed that participants with low-GHGEs diet consumed more plant-based products, in line with findings from other observational studies $(39,40)$. However, for consumption of sweet or fatty products, no difference was detected across quintiles. In contrast to the study of Temme et al. (40), participants with lower GHGEs diets had slightly higher intakes of alcoholic beverages. Of note, participants of our cohort presented low consumption of unhealthy food (alcohol and sweet or fatty products) (44). This may be explained by a potential desirability bias often observed in self-reported dietary records or 
by specific profiles of volunteers in the cohort. Even though alcohol and sweet or fatty food have low impacts on the environment compared to animal products, their intakes provide low nutritionally benefits and their consumption is thus limited in nutritional recommendations (45).

It is now well documented that the overall quality of the diet (as assessed herein with two dietary scores) decreases with increasing GHGEs $(13,43,46)$. In our study, the highest PANDiet score observed in low GHG 'emitters' was mostly explained by the highest subscore related to moderation (for fat, sugar, salt).Besides, the Q3 exhibited the highest subscore related to nutrient adequacy, meaning participants generally presented the lowest probability of having nutrient deficiency. The mPNNS-GS score of Q1 and Q2 were lower than Q3. This result may be explained by the low consumption of animal-based products in these groups. Indeed, the 2001 French nutrition guidelines by promoting a moderate consumption of animal products (one or two servings of meat, fish or egg per day and three servings of dairy products) although vegetarians and low-meat consumers can still meet nutritional needs through appropriate alternative dietary choices (47). Concerning nutritionhealth status, low GHGs 'emitters' exhibited the lowest BMI (Q1 \& Q2). A number of hypotheses may be proposed to explain such observation including healthier dietary patterns as lower overall caloric intake and higher ratio of plant-based to animal-based foods(48). Other studies have identified individual health benefits of low GHGEs or meat diets $(37,49,50)$.

Interestingly, participants in the lowest GHG 'emitters' quintiles, showed the highest consumption of organic food, while the available data of GHGEs in current organic food production showed limited or doubtful benefits (19) depending of the indicators considered. 
In particular, the organic animal-based products these products presented sometimes a greater carbon footprint (mainly due to the longer cycle of production and to lower growth rate (52-54)). However, our results seem to show that heavy organic consumers have a less GHG emitting diet. That can be explained by the overall higher intake of low-GHG foods such as plant-based foods, which is a main characteristic of the organic diet, and may more than compensate for the potential additional GHGEs from some organic production. For others environmental indicators as energy efficiency biodiversity organic farming may present environmental benefits $(18,19)$. Muller et al. concluded that organic agriculture can contribute to decrease environmental impacts only if adequately high proportions of legumes are produced concomitantly with significant reductions of food-competing feed use, livestock product quantities and food wastage (55).

Some limitations should be mentioned. Firstly, participants in the study exhibited specific profiles, as they are volunteers in a long-term cohort focusing on nutrition and health. Participants are likely to display healthier behaviors than in general population. This may have led to an underestimation of unhealthy dietary patterns. However, this specific sample provided an interesting large diversity of pro-environmental dietary behaviors profiles. Secondly, the assessment of food consumption was based on a food frequency questionnaire, which is, as other self-administered methods, prone to measurement error and desirability bias. It is as illustrated, at least partly, by elevated consumption of fruits or vegetables and low levels of unhealthy foods such as sweet or fatty foods and alcohol. Thirdly, environmental database was based on farms registered in DIALECTE on a volunteer basis leading to a potential under representation of farms which are not sensitive to environmental issues and whom the pressures on the environment could be greater. This may have led to an underestimation of environmental impact. However, the high number of 
farms and the use of the median value may have partly overcome this limitation. Only the agricultural production was included in the Life Cycle Assessment, thus transformation, packaging and transport were not taken into account. This limitation should be considered as relative since the major part of environmental impacts generally occur from the agricultural phase (56-58). Some exceptions should be noted such as the alcoholic beverages. However, these foods generally contribute poorly to the total food consumption. Finally, the three environmental indicators assessed do not sufficient reflect all environmental pressures. Other indicators such as eutrophication or biodiversity are important. However, the used of three indicators is an advance because previous studies generally used a single environmental indicator (11). Besides, the study exhibited important contributions. Indeed, scientific literature about the environmental impacts of the diet is growing $(9,10)$, but our study is the first that distinguished modes of production.

In conclusion, based on observed individual data in a large cohort of adults, a low GHGemitting diet appeared to be healthier in terms of nutrition, presents environmental benefits, and is less expensive. Other environmental indicators as the biodiversity footprints or water use are also major indicators which should be accounted in future research including farming practices. 


\section{Acknowledgments}

We especially thank Younes Esseddik, Paul Flanzy, Thi Hong Van Duong, Veronique Gourlet, Fabien Szabo, Nathalie Arnault, Laurent Bourhis and Stephen Besseau, Cédric Agaësse, Claudia Chahine and the Bioconsom'acteurs' members. We warmly thank all of the dedicated and conscientious volunteers involved in the Nutrinet-Santé cohort.

\section{Support}

The NutriNet-Santé study is supported by the French Ministry of Health (DGS), the national public health agency (Santé Publique France), the National Institute for Health and Medical Research (INSERM), the National Institute for Agricultural Research (INRA), the National Conservatory of Arts and Crafts (CNAM) and the University of Paris 13. This study is supported by the BioNutriNet project which is a research project supported by the French National Research Agency (Agence Nationale de la Recherche) in the context of the 2013 Programme de Recherche Systèmes Alimentaires Durables (ANR-13-ALID-0001). Louise Seconda is supported by a doctoral fellowship from the French Environment and Energy Management Agency (ADEME) and the National Institute for Agricultural Research (INRA).

\section{Bibliography}

1. Fifth Assessment Report - Climate Change 2013 [Internet]. [cited 2017 Jul 4]. Available from: http://www.ipcc.ch/report/ar5/wg1/

2. Vermeulen SJ, Campbell BM, Ingram JSI. Climate Change and Food Systems. Annu Rev Environ Resour. 2012 Nov 21;37(1):195-222.

3. Camanzi L, Alikadic A, Compagnoni L, Merloni E. The impact of greenhouse gas emissions in the EU food chain: A quantitative and economic assessment using an environmentally extended input-output approach. J Clean Prod. 2017 Jul;157:168-76.

4. Garnett T. Where are the best opportunities for reducing greenhouse gas emissions in the food system (including the food chain)? Food Policy. 2011 Jan;36:S23-32. 
5. Bryngelsson D, Wirsenius S, Hedenus F, Sonesson U. How can the EU climate targets be met? A combined analysis of technological and demand-side changes in food and agriculture. Food Policy. 2016 Feb;59:152-64.

6. Bryngelsson D, Hedenus F, Johansson D, Azar C, Wirsenius S. How Do Dietary Choices Influence the Energy-System Cost of Stabilizing the Climate? Energies. 2017 Feb 5;10(2):182.

7. Solagro_afterres2050-v2-web.pdf [Internet]. [cited 2017 Jun 6]. Available from: http://afterres2050.solagro.org/wp-content/uploads/2015/11/Solagro_afterres2050-v2web.pdf

8. Communication de la commission au parlement européen, au conseil, au comité économique et social européen et au comité des régions. Feuille de route vers une économie compétitive à faible intensité de carbone à l'horizon 2050 [Internet]. Commission européenne; 2011 [cited $2017 \mathrm{Jul}$ 10]. Available from: http://www.eurosfaire.prd.fr/7pc/doc/1301388482_com_2011_112_fr.pdf

9. Perignon M, Vieux F, Soler L-G, Masset G, Darmon N. Improving diet sustainability through evolution of food choices: review of epidemiological studies on the environmental impact of diets. Nutr Rev. 2017 Jan;75(1):2-17.

10. Aleksandrowicz L, Green R, Joy EJM, Smith P, Haines A. The Impacts of Dietary Change on Greenhouse Gas Emissions, Land Use, Water Use, and Health: A Systematic Review. Wiley AS, editor. PLOS ONE. 2016 Nov 3;11(11):e0165797.

11. Auestad N, Fulgoni VL. What Current Literature Tells Us about Sustainable Diets: Emerging Research Linking Dietary Patterns, Environmental Sustainability, and Economics. Adv Nutr Int Rev J. 2015 Jan 1;6(1):19-36.

12. Masset G, Soler L-G, Vieux F, Darmon N. Identifying Sustainable Foods: The Relationship between Environmental Impact, Nutritional Quality, and Prices of Foods Representative of the French Diet. J Acad Nutr Diet. 2014 Jun;114(6):862-9.

13. van Dooren $\mathrm{C}$, Marinussen $\mathrm{M}$, Blonk $\mathrm{H}$, Aiking $\mathrm{H}$, Vellinga P. Exploring dietary guidelines based on ecological and nutritional values: A comparison of six dietary patterns. Food Policy. 2014 Feb;44:36-46.

14. van Dooren C, Tyszler M, Kramer G, Aiking H. Combining Low Price, Low Climate Impact and High Nutritional Value in One Shopping Basket through Diet Optimization by Linear Programming. Sustainability. 2015 Sep 18;7(9):12837-55.

15. Donati M, Menozzi D, Zighetti C, Rosi A, Zinetti A, Scazzina F. Towards a sustainable diet combining economic, environmental and nutritional objectives. Appetite. 2016 Nov;106:48-57.

16. Hyland JJ, Henchion M, McCarthy M, McCarthy SN. The role of meat in strategies to achieve a sustainable diet lower in greenhouse gas emissions: A review. Meat Sci [Internet]. 2017 Apr [cited 2017 May 23]; Available from: http://linkinghub.elsevier.com/retrieve/pii/S0309174017302176

17. Tuomisto HL, Hodge ID, Riordan $\mathrm{P}$, Macdonald DW. Does organic farming reduce environmental impacts? - A meta-analysis of European research. J Environ Manage. 2012 décembre;112:30920. 
18. Reganold JP, Wachter JM. Organic agriculture in the twenty-first century. Nat Plants. 2016 Feb 3;2(2):15221.

19. Meier MS, Stoessel F, Jungbluth N, Juraske R, Schader C, Stolze M. Environmental impacts of organic and conventional agricultural products - Are the differences captured by life cycle assessment? J Environ Manage. 2015 Feb;149:193-208.

20. Hercberg S, Castetbon K, Czernichow S, Malon A, Mejean C, Kesse E, et al. The Nutrinet-Santé Study: a web-based prospective study on the relationship between nutrition and health and determinants of dietary patterns and nutritional status. BMC Public Health. 2010;10:242.

21. Baudry J, Méjean C, Allès B, Péneau S, Touvier M, Hercberg S, et al. Contribution of Organic Food to the Diet in a Large Sample of French Adults (the NutriNet-Santé Cohort Study). Nutrients. 2015 Oct 21;7(10):8615-32.

22. Kesse-Guyot E, Castetbon K, Touvier M, Hercberg S, Galan P. Relative Validity and Reproducibility of a Food Frequency Questionnaire Designed for French Adults. Ann Nutr Metab. 2010;57(3-4):153-62.

23. Nutrinet-Santé E. Table de composition des aliments de l'étude Nutrinet-Santé. Paris Econ. 2013;

24. Schofield W. Predicting basal metabolic rate, new standards and review of previous work. Hum Nutr Clin Nutr. 1984 Dec;39 Suppl 1:5-41.

25. Verger EO, Mariotti F, Holmes BA, Paineau D, Huneau J-F. Evaluation of a Diet Quality Index Based on the Probability of Adequate Nutrient Intake (PANDiet) Using National French and US Dietary Surveys. PLOS ONE. 2012 Aug 3;7(8):e42155.

26. Chauliac M, Razanamahefa L, Choma C, Boudot J, Houssin D. [National health and nutrition program: challenges of a global action plan]. Rev Prat. 2009 Jan 20;59(1):10-2.

27. Pointereau $P$, Langevin B, Gimaret M. DIALECTE, a comprehensive and quick tool to assess the agro-environmental performance of farms (PDF Download Available) [Internet]. ResearchGate. 2012 [cited 2017 Jun 16]. Available from:

https://www.researchgate.net/publication/265288497_DIALECTE_a_comprehensive_and_quic k_tool_to_assess_the_agro-environmental_performance_of_farms

28. Yield and Retention : USDA ARS [Internet]. [cited 2018 Jan 26]. Available from: https://www.ars.usda.gov/northeast-area/beltsville-md/beltsville-human-nutrition-researchcenter/nutrient-data-laboratory/docs/yield-and-retention/

29. Bognár A. Tables on weight yield of food and retention factors of food constituents for the calculation of nutrient composition of cooked foods (dishes). Bundesforschungsanstalt für Ernährung; 2002.

30. Seconda L, Baudry J, Allès B, Hamza O, Boizot-Szantai C, Soler L-G, et al. Assessment of the Sustainability of the Mediterranean Diet Combined with Organic Food Consumption: An Individual Behaviour Approach. Nutrients. 2017 Jan 12;9(1):61.

31. Attitudes - Français - Kantar Worldpanel [Internet]. [cited 2017 Jul 19]. Available from: https://www.kantarworldpanel.com/fr/Nos-solutions/attitudes 
32. Craig $\mathrm{CL}$, Marshall $\mathrm{AL}$, Sjostrom $\mathrm{M}$, Bauman $\mathrm{AE}$, Booth $\mathrm{ML}$, Ainsworth $\mathrm{BE}$, et al. International Physical Activity Questionnaire: 12-Country Reliability and Validity: Med Sci Sports Exerc. 2003 Aug;35(8):1381-95.

33. Hallal PC, Victora CG. Reliability and validity of the International Physical Activity Questionnaire (IPAQ): Med Sci Sports Exerc. 2004 Mar;36(3):556.

34. Hagströmer M, Oja P, Sjöström M. The International Physical Activity Questionnaire (IPAQ): a study of concurrent and construct validity. Public Health Nutr [Internet]. 2006 Sep [cited 2016 Apr 28];9(06). Available from: http://www.journals.cambridge.org/abstract_S1368980006001261

35. La macro SAS CALMAR | Insee [Internet]. [cited 2018 Jan 9]. Available from: https://www.insee.fr/fr/information/2021902

36. Willett W, Stampfer MJ. Total energy intake: implications for epidemiologic analyses. Am J Epidemiol. 1986 Jul;124(1):17-27.

37. Aston LM, Smith JN, Powles JW. Impact of a reduced red and processed meat dietary pattern on disease risks and greenhouse gas emissions in the UK: a modelling study. BMJ Open. 2012;2(5):e001072.

38. Scarborough P, Appleby PN, Mizdrak A, Briggs ADM, Travis RC, Bradbury KE, et al. Dietary greenhouse gas emissions of meat-eaters, fish-eaters, vegetarians and vegans in the UK. Clim Change. 2014 Jul;125(2):179-92.

39. Soret S, Mejia A, Batech M, Jaceldo-Siegl K, Harwatt $H$, Sabaté J. Climate change mitigation and health effects of varied dietary patterns in real-life settings throughout North America. Am J Clin Nutr. 2014 Jul 1;100(Supplement 1):490S-495S.

40. Temme EH, Toxopeus IB, Kramer GF, Brosens MC, Drijvers JM, Tyszler M, et al. Greenhouse gas emission of diets in the Netherlands and associations with food, energy and macronutrient intakes. Public Health Nutr. 2015 Sep;18(13):2433-45.

41. Hallström E, Carlsson-Kanyama A, Börjesson P. Environmental impact of dietary change: a systematic review. J Clean Prod. 2015 Mar 15;91:1-11.

42. Fazeni K, Steinmüller H. Impact of changes in diet on the availability of land, energy demand, and greenhouse gas emissions of agriculture. Energy Sustain Soc. 2011 Dec 9;1:6.

43. Monsivais $P$, Scarborough $P$, Lloyd T, Mizdrak A, Luben R, Mulligan AA, et al. Greater accordance with the Dietary Approaches to Stop Hypertension dietary pattern is associated with lower diet-related greenhouse gas production but higher dietary costs in the United Kingdom. Am J Clin Nutr. 2015 Jan 7;102(1):138-45.

44. Andreeva VA, Deschamps V, Salanave B, Castetbon K, Verdot C, Kesse-Guyot E, et al. Comparison of Dietary Intakes Between a Large Online Cohort Study (Etude NutriNet-Santé) and a Nationally Representative Cross-Sectional Study (Etude Nationale Nutrition Santé) in France: Addressing the Issue of Generalizability in E-Epidemiology. Am J Epidemiol. 2016 Nov 1;184(9):660-9. 
45. Estaquio C, Kesse-Guyot E, Deschamps V, Bertrais S, Dauchet L, Galan P, et al. Adherence to the French Programme National Nutrition Santé Guideline Score Is Associated with Better Nutrient Intake and Nutritional Status. J Am Diet Assoc. 2009 Jun;109(6):1031-41.

46. Temme EH, Voet $\mathrm{H}$ van der, Thissen JT, Verkaik-Kloosterman J, Donkersgoed $\mathrm{G}$ van, Nonhebel S. Replacement of meat and dairy by plant-derived foods: estimated effects on land use, iron and SFA intakes in young Dutch adult females. Public Health Nutr. 2013 Oct;16(10):1900-7.

47. Melina V, Craig W, Levin S. Position of the Academy of Nutrition and Dietetics: Vegetarian Diets. J Acad Nutr Diet. 2016 Dec;116(12):1970-80.

48. Lassale C, Fezeu L, Andreeva VA, Hercberg S, Kengne A-P, Czernichow S, et al. Association between dietary scores and 13-year weight change and obesity risk in a French prospective cohort. Int J Obes. 2012 Nov;36(11):1455-62.

49. Milner J, Green R, Dangour AD, Haines A, Chalabi Z, Spadaro J, et al. Health effects of adopting low greenhouse gas emission diets in the UK. BMJ Open. 2015 Apr 30;5(4):e007364-e007364.

50. Tilman D, Clark M. Global diets link environmental sustainability and human health. Nature. 2014 Nov 12;515(7528):518-22.

51. Treu H, Nordborg M, Cederberg C, Heuer T, Claupein E, Hoffmann H, et al. Carbon footprints and land use of conventional and organic diets in Germany. J Clean Prod [Internet]. 2017 May [cited 2017 May 24]; Available from:

http://linkinghub.elsevier.com/retrieve/pii/S0959652617309666

52. Nijdam D, Rood T, Westhoek H. The price of protein: Review of land use and carbon footprints from life cycle assessments of animal food products and their substitutes. Food Policy. 2012 Dec 1;37(6):760-70.

53. Kool A, Blonk H, Ponsioen T, Sukkel W, Vermeer H, De Vries J, et al. Carbon footprints of conventional and organic pork : assessments of typical production systems in the Netherlands, Denmark, England and GermanyCarbon footprints of conventional and organic pork : assessments of typical production systems in the Netherlands, Denmark, England and Germany. Blonk Milieuzdvies BV; 2009.

54. Leinonen I, Williams AG, Wiseman J, Guy J, Kyriazakis I. Predicting the environmental impacts of chicken systems in the United Kingdom through a life cycle assessment: Broiler production systems. Poult Sci. 2012 Jan 1;91(1):8-25.

55. Muller A, Schader C, El-Hage Scialabba N, Brüggemann J, Isensee A, Erb K-H, et al. Strategies for feeding the world more sustainably with organic agriculture. Nat Commun [Internet]. $2017 \mathrm{Dec}$ [cited 2017 Nov 24];8(1). Available from: http://www.nature.com/articles/s41467-017-01410-w

56. Clune $\mathrm{S}$, Crossin E, Verghese K. Systematic review of greenhouse gas emissions for different fresh food categories. J Clean Prod. 2017 Jan 1;140, Part 2:766-83.

57. Weidema B., Meeusen MJG. Agricultural Data for Life Cycle Assessments. La Hague, Pays-Bas; 2000. 189 p.

58. Muñoz I, Canals LM i, Fernández-Alba AR. Life cycle assessment of the average Spanish diet including human excretion. Int J Life Cycle Assess. 2010 Sep 1;15(8):794-805. 